University of Wollongong

Research Online

Faculty of Arts, Social Sciences and Humanities

- Papers

Faculty of Arts, Social Sciences \& Humanities

$1-1-2020$

Biosecurity hygiene in the Australian high country: footwear cleaning practices, motivations, and barriers among visitors to Kosciuszko National Park

Nicholas J. Gill

University of Wollongong, ngill@uow.edu.au

Shaun McKiernan

University of Wollongong, sm065@uowmail.edu.au

Anna R. Lewis

University of Wollongong, lewisa@uow.edu.au

Hillary Cherry

Drauzio Annunciato

University of Wollongong, dpa998@uowmail.edu.au

Follow this and additional works at: https://ro.uow.edu.au/asshpapers

Research Online is the open access institutional repository for the University of Wollongong. For further information contact the UOW Library: research-pubs@uow.edu.au 


\title{
Biosecurity hygiene in the Australian high country: footwear cleaning practices, motivations, and barriers among visitors to Kosciuszko National Park
}

\author{
Abstract \\ Conservation areas face growing visitor numbers and heightened biosecurity risks from vectors such as \\ bushwalkers and mountain bikers. For mountain areas, such pressures, with climate change, may be \\ increasing in vulnerability to invasive species. Strategies to manage these risks include encouraging \\ visitors to undertake biosecurity hygiene practices such as cleaning footwear at trailhead cleaning \\ stations. However, limited social science biosecurity hygiene research has been undertaken. We address \\ the issue by using a survey based on a social marketing approach to assess footwear cleaning practices \\ among walkers in Kosciuszko National Park in south-eastern Australia. We identified perceived barriers \\ and benefits to footwear cleaning among walkers, finding a low level of cleaning but that most walkers \\ identified addressing biosecurity risks as a benefit from cleaning. Barriers to cleaning included queues \\ and station maintenance. We use elements from the Theory of Planned Behaviour as a heuristic to reflect \\ on walker behaviour and responses. Outcomes suggest strategies for station installation and design, and \\ the value of further research into visitor norms and behaviour. We reflect on the use of social marketing \\ and what it asks of both visitors and managers.

\section{Publication Details} \\ Gill, N., McKiernan, S., Lewis, A., Cherry, H. \& Annunciato, D. (2020). Biosecurity hygiene in the Australian \\ high country: footwear cleaning practices, motivations, and barriers among visitors to Kosciuszko \\ National Park. Australasian Journal of Environmental Management, Online First 1-19.
}




\begin{abstract}
Conservation areas face growing visitor numbers and heightened biosecurity risks from vectors such as bushwalkers and mountain bikers. For mountain areas, such pressures, with climate change, may be increasing vulnerability to invasive species. Strategies to manage these risks include encouraging visitors to undertake biosecurity hygiene practices such as cleaning footwear at trailhead cleaning stations. However, limited social science biosecurity hygiene research has been undertaken. We address the issue by using a survey based on a social marketing approach to assess footwear cleaning practices among walkers in Kosciuszko National Park in south-eastern Australia. We identified perceived barriers and benefits to footwear cleaning among walkers, finding a low level of cleaning but that most walkers identified addressing biosecurity risks as a benefit from cleaning. Barriers to cleaning included queues and station maintenance. We use elements from the Theory of Planned Behaviour as a heuristic to reflect on walker behaviour and responses. Outcomes suggest strategies for station installation and design, and the value of further research into visitor norms and behaviour. We reflect on the use of social marketing and what it asks of both visitors and managers.
\end{abstract}

Keywords: Invasive species; biosecurity, social marketing; tourism; behavioural change 


\section{Introduction}

Invasive plants, animals, and pathogens continue to be readily transported both globally and within nations through human activity (Bullock and Pufal 2020; Seebens et al. 2017). The vectors for distribution are diverse and associated with transport, trade, vehicles, agricultural machinery, animal feed, farm production, and recreational activities such as walking, horseriding and mountain biking (Coleman et al. 2011; Anderson et al. 2015; Mount and Pickering 2009; Pickering and Mount 2010; Pickering, Ansong, and Wallace 2016). For public lands, particularly protected areas, recreational activities can be a means by which weed seeds and pathogens are transported across and within boundaries (Ansong and Pickering 2014; Weiss, Brummer, and Pufal 2016). Many weed seeds adhere to footwear, laces, socks, trousers, and to mountain bike frames and tires. At a global scale, recreational activities in protected areas are associated with 'significantly higher' abundance and richness of non-native species than in other sites (Anderson et al. 2015, p.8). As nature-based tourism increases globally (Pickering et al. 2018) and as recreational activities develop (Burgin and Hardiman 2012), the potential for transport of invasive species to new areas, and spread within areas where they are already present, is enhanced.

The distribution of plants seeds through recreation is evident in Australian parks and reserves, including high country parks in south-eastern Australia. For example, tourism related infrastructure (e.g. ski resorts and associated gardens and road verges) is characterised by large numbers of non-native species (Pickering, Bear, and Hill 2007). Back country huts used by hikers and cross-country skiers are also environments likely to be associated with the introduction of non-native plants (Morgan and Carnegie 2009).

One strategy for park managers to reduce the risk of seed and pathogen distribution is to influence the behaviour of diverse park visitors. This can be challenging in parks with high visitor numbers, diverse activities, and multiple entry points. Park managers are often unable to directly regulate visitor behaviour and must indirectly influence behaviour (Ham et al. 2009; Schwartz et al. 2018). The means of doing this are generally by provision of trailhead facilities such as footwear cleaning stations (Figure 1), which usually incorporate brushes and a spray mechanism for the delivery of a biocide to footwear, and associated information and signage. However, as the provision of facilities and information will not necessarily lead to high rates of use (Boon, Fluker, and Wilson 2008), key issues include how infrastructure is designed and installed, how information about the need for cleaning is presented, and how it relates to visitor beliefs about their behaviour (Curtis, Ham, and Weiler 2010). 
Figure 1 Footwear cleaning station of a design used in Australia about here

In this article, we examine current cleaning practices by walkers, and identify their perceived barriers to, and benefits of, cleaning footwear when walking in Kosciuszko National Park (KNP), New South Wales (NSW), Australia (Figure 2). The research is part of an eradication program for orange hawkweed (Hieracium aurantiacum L.) and mouse-ear hawkweed $(H$. pilosella L.) in NSW and in KNP specifically (Hamilton, Cherry, and Turner 2015), which includes plans to install footwear cleaning stations in KNP. We focus on footwear cleaning practices by walkers in the absence of cleaning stations. Our aim is to provide insights into current views and awareness of biosecurity among park visitors as biosecurity management in protected areas is increasingly assuming greater importance. A sub-aim is provide evidence to inform station installation practice and associated signage that will maximise the uptake of weed hygiene practices. Generally, we aim to build upon the largely biophysical literature concerning outdoor recreationalists as vectors of weed distribution, to develop the sparse social science literature on weed hygiene practices (Gill et al. 2018), and to address the relative absence of biosecurity matters in tourism practice and research (Hall 2015). 


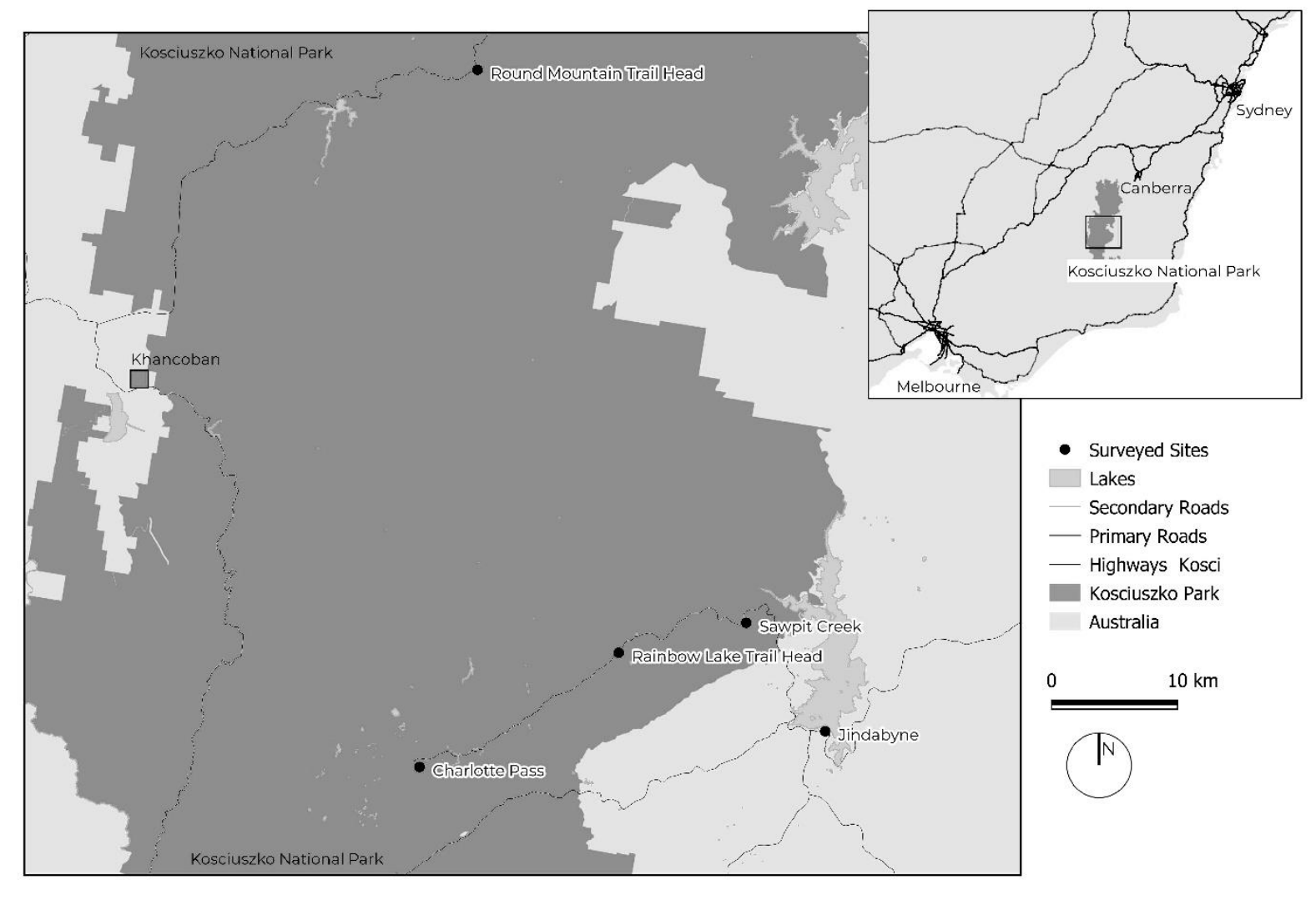

Figure 2 Location of Kosciuszko National Park and survey locations about here.

\section{Biosecurity hygiene, recreation, and protected areas}

\section{Biosecurity practices in the tourism industry}

The tourism industry, research institutions and governments have paid little attention to biosecurity and to managing potential tensions between facilitating tourism and managing access and behaviour (Hall 2015). Gaps in practice, information provision, and institutional arrangements are common (Baird, Hall and Castka, 2018; Hall, 2011, Hall, James and Wilson, 2010). Nonetheless, globally there are efforts being made to manage visitors and influence their behaviour to reduce the spread of invasive species (Anderson et al. 2015). These include codes of practice, luggage inspection, boat disinfection protocols, and a range of visitor awareness raising and education initiatives (Anderson et al. 2015). New Zealand (NZ) has established programs and infrastructure to address biosecurity issues such as cleaning stations at national park trailheads (Aley and MacDonald 2018). In Australia, cleaning stations are common in Tasmania and Western Australia and associated with reducing the spread of the pathogen Phytophthora. Such stations allow visitors to brush down and/or disinfect clothing and 
footwear to remove weed seeds, soil, vegetation, and pathogens that may have adhered to them. Such practices are among those referred to as hygiene practices (Gill et al. 2018) and we refer to them here as biosecurity hygiene to encompass pathogens as well as invasive plants.

Apart from NZ, research related to biosecurity hygiene is generally focused on the vectors and pathways of spread (Coleman et al. 2011; Ansong and Pickering 2014), with little study of social, attitudinal and behavioural aspects of hygiene practices (Gill et al. 2018). Given the resources going into biosecurity hygiene such as the installation of footwear and mountain bike cleaning stations in many protected areas and elsewhere, it is important to ensure that the objectives for these investments are achieved. Generally, the limited social research suggests that, in the absence of specific measures such as group management (Rumpf, Alsos, and Ware 2018), few visitors to protected or natural areas adopt biosecurity hygiene practices. This includes recreationalists such as anglers (Gates et al. 2009), visitors to the Artic (Ware et al. 2012), agency staff and researchers (Shannon et al. 2018), and workers in tree industries (Marzano et al. 2016). These findings reflect those for Australia where weed hygiene practices in relevant Australian industries and organisations are inconsistently implemented and practiced (Gill et al. 2018) and that broader publics in the UK are only 'moderately willing to adopt biosecurity measures (Urquhart et al. 2017).

The most detailed tourism related research on biosecurity hygiene practices is reported in compliance-oriented grey literature from New Zealand. This research has largely focussed on footwear cleaning station installation as part of the Kauri (Agathis australis) Dieback Programme (Benson and Dixit 2010; Colmar Brunton Consultants 2016; Wegner 2014). Following poor compliance at previously installed stations, this work was undertaken to monitor the level of track user compliance at new prototype cleaning stations. Aley and MacDonald (2018) report that 90 per cent or more of walkers did 'something' (i.e. used the cleaning station at least partially instead of walking through or around it) to clean their shoes. In a longer-term monitoring study from 2011-2016, higher rates of awareness of Kauri dieback did not necessarily translate to improved compliance in cleaning station use (Colmar Brunton Consultants 2016). However, intentions among visitors to use cleaning stations in the future were very high (Wegner 2014). Across this research, barriers to compliance among visitors included doubt as to efficacy of cleaning practices, inadequate information, the effort required to comply, questions as to the role of humans as vectors relative to other processes, lack of maintenance of cleaning stations, and general lack of awareness of the issue of Kauri dieback. Reasons for compliance included protecting Kauri and 'natural heritage', obligations 
to follow instructions, and simplicity of compliance. Similarly, for KNP visitors, our research sought to document existing hygiene practices, intentions, and barriers to, and reasons for, cleaning footwear.

Kosciuszko National Park: values, visitors, and weeds

Kosciuszko National Park (KNP) is in the Snowy Mountains region of the Australian Alps in southern New South Wales (NSW). The park (673,542 ha) is the largest national park in NSW and one of the largest conservation reserves in Australia (Department of Environment and Conservation 2006). The park has high conservation value; a status recognised in its listing as a UNESCO Biosphere Reserve, the listing of Blue Lake in the Main Range area under the Ramsar Convention, and international recognition as a significant centre of biodiversity (Department of Environment and Conservation 2006).

Since European settlement, the park area has seen a series of uses and developments including grazing, mining, hydroelectric development, ski resort development, and activities such as bushwalking and mountain biking. The park is one of the most visited protected areas in Australia. Visitor numbers have been growing for many years (Johnston and Growcock 2005) and continue to do so, jumping from 1,449365 in 2014 to 2,196,525 in 2016 (Stephanie Martin, NPWS, pers. comm. 20/8/18). By far the majority of visitors are domestic - available, if somewhat dated, survey data shows that only 1-3\% of visitors are from overseas (Johnston and Growcock 2005).

While there are many weeds in the Australian Alps, the alpine area of KNP has historically been relatively free of weeds (McDougall et al. 2005). Nonetheless, activities since European settlement have led to the introduction of exotic plant species into the park, including via recreational activities, notably the ski industry (Bear, Hill, and Pickering 2006). Recent introductions such as hawkweeds have highlighted the ongoing pathways for potential new introductions (Kueffer et al. 2013) and the need for preventative measures as part of management (Alexander et al. 2016). As hiking in KNP is a potential source of ongoing plant introductions (Pickering et al. 2011), and mouse-ear hawkweed is thought to have been introduced to KNP by hikers (Hamilton, Cherry, and Turner 2015), such measures need to encompass the behaviour of visitors such as walkers. 


\section{Methods}

In NSW the methodology of community-based social marketing (CBSM) is being used by agencies in invasive species management including in the KNP area. Community-based social marketing is an approach to social marketing for behaviour change developed by MackenzieMohr (2011) that prioritises understanding citizen perspectives on public good issues and tailoring communication and/or other engagement to effect changes in behaviour. It builds on and echoes research regarding the well-known gap between environmental knowledge/attitudes and behaviour (Kollmuss and Agyeman 2002; Juvan and Dolnicar 2014), the apparent but deceptive simplicity of 'pro-environmental' behaviour (Martin et al. 2017), and the pitfalls of assuming that a lack of action on the part of 'publics' simply reflects a lack of knowledge (Eriksen and Gill 2010). In NSW and the KNP area, this program is attempting to improve invasive plant management and to move beyond reliance on conventional education and enforcement (Verbeek, van Oosterhout, and Gibney 2018) and a simplistic assumption (Ansong and Pickering, 2015) that lack of action reflects a lack of knowledge or awareness about invasive plants.

The use of behavioural approaches and social marketing techniques outside of commercial applications is increasingly common in a range of social (Randle et al. 2016) and environmental applications (McKenzie-Mohr 2000; Martin et al. 2017; Font and McCabe 2017), including for weed management (Martin and Hine 2017; Verbeek, van Oosterhout, and Gibney 2018; Hu and Gill 2016). Improved communication is a critical issue for sustainability in tourism in general (Tölkes, 2018) and social marketing tools have been used to some extent to address protected area management (see, e.g., Curtis, Ham, and Weiler 2010; Steckenreuter and Wolf, 2013) While questions remain as to whether and how social marketing-based approaches can deal with the structure, complexity, and temporalities of some environmental issues and behaviours (Green et al. 2019; Hobson 2017; Biroscak 2018; Truong and Hall 2017), there is evidence that marketing approaches can effectively target and change environmental behaviours (Hall 2015; Metcalf et al. 2019), particularly where part of a broader strategy (Tapp and Rundle-Thiele 2016).

A key foundation to CBSM are the insights from the Theory of Planned Behaviour (TPB; Ajzen 1991) and associated approaches. While TPB can yield mixed results and its explanatory power can be variable and context dependent (Vagias et al. 2014; Juvan and Dolnicar 2014), for our purposes it provides a useful heuristic to frame our approach and results. In essence, the TPB suggests that behaviour is "primarily guided by three categories of beliefs: 'behavioural beliefs' 
about the likely outcomes of the behaviour and a person's evaluations of these outcomes; 'normative beliefs' about the opinions of important social referents (e.g. partners, friends, specific organisations) regarding the behaviour and a person's motivation to comply with these opinions; and 'control beliefs' about the presence and control of factors that may facilitate or impede the performance of the behaviour" (Curtis, Ham, and Weiler 2010, p.566). Theoretically, the TPB suggests that if an opportunity is provided to someone to carry out a behaviour, three things needs to be in place for that person to be likely to actually do so: (1) positive attitudes towards the behaviour; (2) a favourable response to pressure to carry out the behaviour; and (3) a sense of control over actually carrying out the behaviour (Fishbein and Ajzen 2011). The implication for behavioural change is that messages and implementation of an intervention must target these attitudes, and the normative and control beliefs, to generate intentions to undertake the behaviour.

Guided by this use of the TPB framework, this research on walkers represents an elicitation study as a step in a process of implementing an intervention aimed at generating high rates of biosecurity compliance among walkers. Such elicitation studies are a critical and sometimes ignored first step in this process (van den Putte and Dhondt 2005; Curtis, Ham, and Weiler 2010; McKenzie-Mohr 2011). As the goal of this elicitation step is to identify salient beliefs among, and terminology used by, the target population that can be used in subsequent fixed item survey instruments and possibly messaging, they are commonly either open-ended or qualitative in format (Middlestadt et al. 1996; Curtis, Ham, and Weiler 2010).

Accordingly, we conducted a short verbal intercept survey that included the following characteristics: (a) a mix of open-ended and closed response questions; (b) delivery at a relatively remote trailhead frequented by overnight walkers and at what we expected to be higher visitation sites frequented by many day visitors; and (c) questions that explored the perceived barriers and benefits to cleaning footwear using various cleaning methods. The survey was introduced to potential respondents as being concerned with 'track management', weeds and pathogens were not mentioned.

The survey was delivered over two weekends in the late southern hemisphere summer of 2018 at the relatively remote Round Mountain trailhead and in a heavily visited part of the park along the Kosciusko Road between Jindabyne (the nearest town and a centre for regional tourism) and Charlotte Pass (Figure 2). In total 116 walkers participated in the survey (Table 1). Poor weather led to the Kosciuszko Road sites being abandoned and thirty-seven subsequent surveys 
that weekend were carried out at the visitor centre in Jindabyne. Here we screened visitors by first asking if they had walked, or intended to walk, in KNP.

\section{Table 1 Survey Locations in Kosciuszko National Park and Jindabyne}

\begin{tabular}{lll}
\hline$\underline{\underline{\text { Location }}}$ & $\underline{\underline{\text { Frequency }}}$ & $\underline{\text { Percentage }}$ \\
\hline$\underline{\text { Kosciusko Road: Charlotte Pass }}$ & $\underline{39}$ & $\underline{33.6}$ \\
$\underline{\text { Kosciuszo Road sites: Sawpit Creek/Rainbow }}$ & $\underline{10}$ & $\underline{8.6}$ \\
$\underline{\text { Lake/Rennix Gap }}$ & $\underline{37}$ & $\underline{31.9}$ \\
$\underline{\text { Jindabyne Visitor Centre }}$ & $\underline{30}$ & $\underline{25.9}$ \\
$\underline{\text { Round Mountain }}$ & $\underline{116}$ & $\underline{100.0}$ \\
\hline$\underline{\text { Total }}$ &
\end{tabular}

Table 1. about here

Subsequent analysis involved recoding the responses from the open-ended questions, generating descriptive statistics for key variables such as the current extent of footwear cleaning, and using bivariate analysis to test for differences between groups such as those who clean and those who do not, and between locations. Small numbers for some groups meant that we had to recode and combine some data; for example, data for the sites along Kosciuszko Road.

\section{Results}

Do walkers clean their footwear?

We asked respondents if they cleaned their footwear before and after a walk. Overall the rate of cleaning is low (Table 2). Almost 60 per cent $(n=116)$ said they never cleaned their footwear before a walk. Overall, 86.2 per cent of respondents $(n=100)$ cleaned their footwear sometimes, only occasionally, or never (we refer to these as 'non-cleaners'), before a walk. In contrast only 13.8 per cent of respondents $(n=16)$ cleaned their footwear at least half the time (we refer to these as 'cleaners') before a walk. Of those respondents who do, or have cleaned their boots 
before a walk, 36.2 per cent indicated they use a fixed boot brushing station, 21.3 per cent use a brush provided at the trail head, and 8.5 per cent bring a brush with them. However, the second highest response was 'Other' (34\%), indicating a high proportion of walkers do not use any of the suggested cleaning options. The cleaning methods associated with 'other' were largely ad hoc, including walkers banging their boots together, or using their hands (50\%). This involved using sticks, a towel, wiping on grass, and similar methods that were primarily carried out at the site. Cleaning boots at home using a water or brush was the second most common method in the 'other' category $(31.3 \%)$.

\section{$\underline{\text { Table } 2}$}

Walkers cleaning practice before and after a walk, percentage of respondents $(n=116)$

\begin{tabular}{|c|c|c|c|c|c|c|}
\hline & Always & $\begin{array}{l}\text { Often, but } \\
\text { not all the } \\
\text { time }\end{array}$ & $\begin{array}{l}\text { About half } \\
\text { the time }\end{array}$ & $\underline{\text { Sometimes }}$ & $\begin{array}{l}\text { Only } \\
\text { occasionally }\end{array}$ & Never \\
\hline Before a & $\underline{4.3}$ & $\underline{7.8}$ & $\underline{1.7}$ & 16.4 & $\underline{10.3}$ & $\underline{59.5}$ \\
\hline$\underline{\text { Walk }}$ & & & & & & \\
\hline $\begin{array}{l}\text { After a } \\
\underline{\text { Walk }}\end{array}$ & $\underline{11.2}$ & $\underline{9.5}$ & $\underline{6.0}$ & $\underline{22.4}$ & $\underline{17.2}$ & $\underline{33.6}$ \\
\hline
\end{tabular}

\section{Table 2. about here}

In comparison to before a walk, survey respondents were more likely to clean their boots after a walk (Table 2). Overall, 73.2 per cent were non-cleaners, cleaning their footwear sometimes, only occasionally, or never after the walk, and 26.8 per cent were cleaners. Respondents were almost three times more likely to "always" clean after a walk. Of the respondents who do, or have cleaned their boots after a walk, only 3.9 per cent brought a brush with them, 11.7 per cent use a brush provided at the trailhead, and 22.1 per cent use a fixed boot brushing station. Other $(62.3 \%)$ was the highest response. Like before the walk, this included cleaning boots at home using a water and brush (30.4\%), or using hands (sticks, wiping on grass, towel etc.) or banging boots together, most commonly in the car park (54.3\%). 
Overall, there is considerable overlap between the two groups; 79 individuals (68\%) of respondents said that they cleaned their footwear sometimes, only occasionally, or never both before and after a walk. In contrast only five individuals said they always cleaned their footwear both before and after a walk.

We also tested for differences in cleaning behaviour between different visitor groups. First, we asked respondents to self-rate their knowledge of weeds in national parks. While those who rated their knowledge as 'high' or 'very high' did clean their footwear to a greater extent than those who rated their knowledge as less than high (e.g. $22 \%$ and $10 \%$, respectively before a walk), this was not statistically significant both before $\left(x^{2}(1)=2.800, \mathrm{p}=0.094\right)$ and after $\left(x^{2}(1)\right.$ $=1.963, \mathrm{p}=0.161)$ a walk. We also compared responses from Round Mountain to the other locations but there was little difference, and it was not statistically significant, in the extent to which respondents were cleaners or non-cleaners.

Second, as the behaviour of international visitors is of interest to park managers, we asked if respondents were Australian residents or visitors to Australia. While the number of respondents who were international visitors was small $(n=11)$, the results are potentially informative. No international visitors cleaned their footwear before a walk and in this respect, they were not substantially or significantly different from Australian residents, most $(84.6 \%, \mathrm{n}=105)$ of whom also do not clean their footwear. However, the international visitors do clean their footwear to a greater extent (54.5\%) after a walk than Australian residents (23.1\%). While these numbers of international visitors are small, this difference is statistically significant (Fisher's Exact Test $\mathrm{p}=0.034)$. The only benefit from cleaning for which international visitors substantially and significantly exceed Australian residents (Fisher's Exact Test $\mathrm{p}=0.036$ ) is 'clean car/house'. International visitors (63.6\%) indicated that this was a benefit of cleaning footwear after a walk as compared to $28.8 \%$ of Australian residents.

Will walkers clean their footwear if advised to do so?

We asked walkers how likely they were to clean their footwear if advised to do so. Overall, most respondents indicated that they would be 'very likely' (71.6\%) or 'somewhat likely' $(20.7 \%)$ to clean footwear before a walk. Similarly, all survey respondents indicated a high likelihood of cleaning their boots after a walk if advised to do so, with 63.8 per cent 'very likely to do this' and 24.1 per cent 'somewhat likely to do this'. There was little difference between locations for likelihood of cleaning before or after a walk, although walkers at Round Mountain were less likely to clean after a walk. For example, 73.4 per cent of respondents $(n=30)$ at 
Round Mountain were 'very' or 'somewhat likely' to clean after a walk, compared to 93 per cent of respondents $(n=86)$ at the other locations. Self-rated knowledge of weed impacts in national parks was not significantly different for respondents' likelihood of cleaning footwear before (Fisher's exact test $\mathrm{p}=0.407$ ) or after a walk (Fisher's exact test $\mathrm{p}=0.480$ ).

Even though non-cleaners $(n=100)$ do not currently clean their footwear, their responses indicate that most are likely to clean footwear if advised to do so. If advised, 91 per cent are 'somewhat likely' or 'very likely' to clean their boots before a walk and only 5 per cent indicated that they 'probably would not' do this even if advised. For after a walk, 88 per cent answered that they are 'somewhat likely' or 'very likely' to clean their boots if advised, and only 7.1 per cent indicated that they 'probably would not' even if advised.

What are the perceived barriers to cleaning footwear?

We asked open ended questions regarding perceived barriers to cleaning footwear. We recoded the answers into the categories in Table 3. Lack of cleaning facilities was the most common barrier identified both before and after a walk - 42.2 and 51.7 per cent of all respondents respectively. This suggests that providing cleaning facilities is likely to assist in overcoming perceived barriers, including if the facilities simply act to remind people and make cleaning a routine part of walking. Quality of clean refers to walkers finding it difficult to clean their footwear due to the design of the equipment or due to some aspect of their footwear. This issue came up in related ways in other questions and we will discuss this further below. Fatigue at the end of the walk refers to feeling tired and preferring to go straight home rather than completing a further task.

\section{$\underline{\text { Table } 3}$}

Barriers to brushing all of the vegetation and dirt off your boots/ footwear at the trailhead before/after a walk, percentage of respondents $(n=116)$. Columns sum to more than 100 as some respondents provided more than one answer to an open-ended question

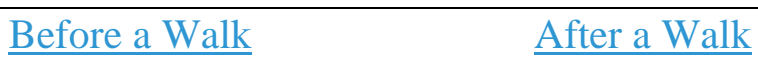

Lack of facilities/equipment

$\underline{\text { Remembering/Habit }}$

$$
\underline{42.2}
$$

23.3.
51.7

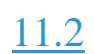




\section{Table 3. about here}

With respect to the differences between cleaners $(n=100)$ and non-cleaners $(n=16)$, noncleaners tended to emphasise a lack of facilities or equipment as a barrier compared to cleaners. For example, before a walk, 18.8 per cent of cleaners perceived facilities/equipment to be a barrier compared to 46 per cent of non-cleaners $\left(x^{2}(1)=4.198, p=0.040\right)$. A statistically significant difference (Fisher's exact test, $p=0.024$ ) also existed between cleaners and noncleaners for quality of clean before walk. In this case, cleaners $(37.5 \%)$ were more likely to find this a barrier than non-cleaners $(13 \%)$.

For a provided handheld brush or a cleaning station (the most likely options for a trailhead), the barriers that respondents identified particularly provide useful insights to those issues that might mitigate against footwear cleaning. While for both cleaning methods almost half of all respondents said there were no barriers to use, respondents did identify various maintenance and cleanliness issues as barriers to use for both methods (Table 4). The issue of queues and waiting time as a barrier may be important to large groups and/or at busy sites. This may necessitate installing multiple sets of cleaning equipment as occurs at some NZ trailheads. The barrier of 'difficult to use' refers to responses regarding cleaning station location and access as well as knowing how to use it

\section{Table 4}

Perceived barriers to using a provided handheld brush and a fixed brush cleaning station, percentage of respondents $(n=116)$. Rows sum to more than 100 as some respondents provided more than one answer to an open-ended question 


\section{$\underline{\text { Poor }}$}

\begin{tabular}{|c|c|c|c|c|c|}
\hline \multirow{2}{*}{\multicolumn{2}{|c|}{$\begin{array}{l}\text { Provided } \\
\text { handheld }\end{array}$}} & \multicolumn{4}{|l|}{$\underline{\text { condition }}$} \\
\hline & & llack & & Cross & \\
\hline brush & $\underline{\text { Nothing }}$ & $\underline{\text { maintenance }}$ & Queue & $\underline{\text { contamination/dirty }}$ & Other \\
\hline & 49.1 & 30.2 & 17.2 & 12.9 & 10.3 \\
\hline
\end{tabular}

\begin{tabular}{|c|c|c|c|c|c|}
\hline \multicolumn{6}{|c|}{ Fixed brush } \\
\hline cleaning & & Difficult to & Cleanliness/ & & \\
\hline station & Nothing & use & maintenance & Queue & Other \\
\hline & 43.1 & $\underline{19.0}$ & $\underline{19.0}$ & $\underline{18.1}$ & $\underline{10.3}$ \\
\hline
\end{tabular}

\section{Fable 4. at here}

What are the perceived benefits for cleaning footwear?

We asked walkers what they thought the benefits of footwear cleaning before and after a walk might be. We placed their responses into categories, including four that related to biosecurity. 'Stop weed/seed spread' refers to instances where respondents explicitly used the words 'weed' or 'seed' in their answers. 'Prevent contamination' captures walkers specifically stating 'contamination' in their answer. Stopping 'pathogens' indicates survey respondents explicitly referred to either pathogens or disease in their answer. 'Environmental protection' refers to instances when survey respondents used less specific terms such as foreign material or nonnatives. Most survey respondents identified at least one of these biosecurity reasons as a benefit in brushing footwear at the trailhead. For before a walk, 91.4 per cent of all respondents nominated a biosecurity reason as a benefit for cleaning. After the walk, 67.2 per cent of all respondents nominated a biosecurity reason as a benefit for cleaning. The majority of respondents nominated controlling the spread of noxious weed seeds and pathogens as the primary benefits (Table 5). For example, over half of all respondents identified stopping weeds or seed spread as a benefit of cleaning before a walk. Additionally, 31.9 per cent of all respondents also noted having a clean car/house as a benefit from brushing their boots after a walk. 


\section{Table 5}

Perceived benefits in brushing all of the vegetation and dirt off your boots at the trailhead, percentage of total respondents. Columns sum to more than 100 as some respondents provided more than one answer to an open-ended question. 'Other' includes reasons such as footwear care, being ready for the next walk, and unsure $(n=116)$.

\begin{tabular}{lll}
\hline & $\underline{\text { Before a Walk }}$ & $\underline{\text { After a Walk }}$ \\
\hline$\underline{\text { Stop weed/seed spread }}$ & $\underline{53.4}$ & $\underline{43.1}$ \\
$\underline{\text { Clean house/car }}$ & $\underline{\mathrm{NA}}$ & $\underline{31.9}$ \\
$\underline{\text { Prevent contamination }}$ & $\underline{27.6}$ & $\underline{17.2}$ \\
$\underline{\text { Stop pathogens }}$ & $\underline{17.2}$ & $\underline{12.1}$ \\
$\underline{\text { Environmental Protection }}$ & $\underline{9.5}$ & $\underline{\mathrm{NA}}$ \\
$\underline{\text { Other }}$ & $\underline{11.2}$ & $\underline{12.9}$ \\
\hline
\end{tabular}

Table 5. about here

While cleaners tended to have slightly greater awareness about the prevention of weed/seed spread as a benefit of footwear cleaning, the differences between cleaners $(n=16)$ and noncleaners $(n=100)$ were not statistically significant. For example, before a walk 68.8 per cent of cleaners and 51 per cent of non-cleaners identified stopping weeds/seed spread as a benefit but this was not statistically significant $\left(x^{2}(1)=1.747, \mathrm{p}=0.186\right)$. With respect to location, respondents at Round Mountain tended to identify biosecurity benefits to a greater extent than respondents at other locations however, before a walk this was only significant for stopping weed/seed spread (Table 6).

\section{$\underline{\text { Table } 6}$}

Benefits of cleaning footwear before a walk by location, percentage of respondents. Columns sum to more than 100 as some respondents provided more than one answer to an open-ended question 


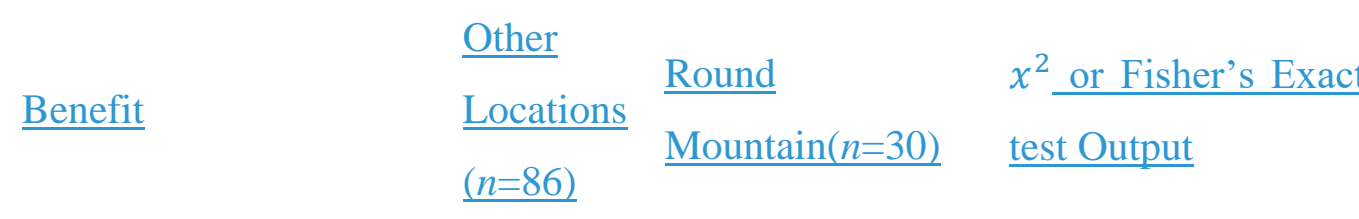

$\underline{\underline{\text { Stop weed/seed spread }} \quad \underline{45.3 \%} \quad \underline{76.7 \%} \quad x^{2}(1)=8.767, \mathrm{p}=.003}$

$\underline{\text { Prevent contamination } \quad \underline{31.4 \%} \quad \underline{16.7 \%} \quad x^{2}(1)=2.415, \mathrm{p}=.120}$

$\underline{\text { Stop pathogens } \quad \underline{16.3 \%} \quad \underline{20.0 \%} \quad x^{2}(1)=.216, p=.642}$

Environmental

Protection

$\underline{10.5 \%} \quad \underline{6.7 \%}$

Fisher's exact test,

$\mathrm{p}=.726$

$\underline{\text { Other }}$

$\underline{9.3 \%} \quad \underline{16.7 \%}$

Fisher's exact test,

$\underline{p=.316}$

Table 6. about here

\section{Discussion}

Consistent with pre-intervention rates of footwear and equipment cleaning elsewhere, rates of cleaning footwear in KNP are very low. Only five individuals (4.3\%) among survey respondents cleaned their footwear both before and after a walk. Most walkers are not cleaning their footwear either before or after a walk. Cleaning is more likely to occur after a walk than before; this possibly reflects a desire to not track dirt or other material into their car or home, which was identified as one of the benefits of cleaning footwear after a walk and which may help to account for higher rates of cleaning among international visitors. For these visitors, this may be a function of wanting to stay as clean as possible while travelling when washing and laundering may be difficult or inconvenient. It may be related to norms in their home countries regarding cleaning or it may be due to recent exposure to biosecurity information while travelling.

While we did not collect data on perceptions of footwear cleanliness, the higher rate of cleaning after a walk may also reflect a perception among walkers that their footwear is clean before a walk, and therefore free of seed and pathogens, and that there is no need to clean it before setting out. Even so, for those who do clean after a walk, they commonly do so in the car park. 
This practice does spatially contain any weeds or pathogens to some extent but presents the risk of depositing seeds in the car park.

Self-assessed knowledge of the impact of weeds in national parks is not associated with cleaning practice. Moreover, despite a higher awareness of the biosecurity benefits of footwear cleaning by Round Mountain walkers, there is no significant difference between the cleaning practices of walkers at different locations. To the extent that these locations are generally used by different types of walkers, such as day walkers at Charlotte Pass and overnight walkers at Round Mountain, this suggests that such differences among walkers may not be central to cleaning behaviour. Overall, our results suggest that greater knowledge and awareness of weed impact and of the benefits of weed hygiene does not necessarily translate to higher implementation of weed hygiene practices. This is consistent with our more general finding that cleaners and non-cleaners were not significantly different in the extent to which they identified benefits of footwear cleaning.

Despite our finding that walkers are not cleaning their footwear to any great extent in the absence of facilities, most respondents indicated that they would clean their footwear if advised to do so. While these figures may provide an expression of intentions, it suggests that even non-cleaners may clean their boots if appropriate information and facilities are provided. Nonetheless, there is a small group who are unlikely to clean their footwear even if advised to do so. This echoes outcomes in NZ where around 5 per cent of walkers have been observed to not use cleaning stations on tracks even where this means that walkers do not stop to clean footwear as they pass through cleaning stations installed across the track (Aley and MacDonald 2018).

Most respondents identified biosecurity issues, framed in some way, as a benefit of cleaning their footwear. Most commonly, preventing the spread of 'weeds or seeds' was mentioned as a reason to clean. The types of walkers at Round Mountain appear to have a greater awareness of the possibility that walkers can act as weed vectors, suggesting that further investigation into how walkers are differentiated with respect to how they conceive of biosecurity issues, and any consequences of this, is warranted. Generally, there is a high level of awareness of biosecurity in some form as a reason to clean footwear, and the idea that walkers can represent a biosecurity risk is widely understood among walkers in KNP.

Following the CBSM approach and given our elicitation goals, we framed the survey relatively simply in terms such as barriers and benefits. While we are therefore not formally testing in 
terms of the TPB, our results are suggestive of elements of the TPB and provide insights that can be further tested, particularly where cleaning stations are installed. First, among walkers there are attitudes towards footwear cleaning that could be characterised as positive (behavioural beliefs). Walkers were generally willing to clean footwear and able to articulate reasons to do so. Such information may be useful in developing messaging at trailheads that invokes norms regarding footwear cleaning as a practice that is agreed upon and should be done for reasons that are shared by, or appeal to, walkers (normative beliefs). Second, while we did not specifically ask about views on the effectiveness of footwear cleaning for biosecurity hygiene, walkers volunteered forms of biosecurity hygiene as a reason to clean footwear suggesting that at least they perceive it as an action that can be undertaken to address biosecurity hygiene goals (behavioural beliefs). Future research should focus more specifically on walkers' perceptions of the efficacy of footwear cleaning, particularly in the context of installed cleaning stations.

Third, and related to efficacy and to a sense of behavioural control over footwear cleaning, many respondents saw no barriers to using cleaning equipment. Others, however, mirroring NZ, identified several potential barriers to using provided cleaning equipment (control beliefs). Such barriers included the condition of cleaning equipment, queues, location, and clarity of instructions. Cleaners had relatively high levels of concern about the quality of clean. Such perceptions could be tested where cleaning stations are installed to highlight the importance of ensuring cleaning stations are installed that are easy to use and can be operated in a manner perceived by walkers to be effective in fulfilling the request to clean footwear. As perceived control can be more important than intention in influencing park visitor behaviour (Schwartz et al. 2018), such issues also emphasise the need for park managers to accrue credibility by providing sufficient cleaning equipment and maintaining cleaning equipment. Walkers are more likely to then receive a message that park managers are serious about footwear cleaning and thereby feel, that in going to the effort of complying with the request to clean footwear, their cleaning efforts are going to be effective. This highlights more general issues regarding the place of CBSM and its use, such as within park management. While our research suggests strategies for improved communication and messaging, such strategies are unlikely by themselves to adequately address behavioural change for biosecurity hygiene. Framing problems of invasive species in diverse ways is a social process (Head 2017). The adoption of CBSM in invasive species management is, in part, premised on recognising diverse 
perspectives on invasive species and changing the approach to management based on this acknowledgement (Verbeek, van Oosterhout, and Gibney 2018).

There are at least two dimensions of these issues that are relevant here; both of which present challenges, even where the 'audience' has relatively high awareness of biosecurity and where a knowledge deficit is not particularly evident. First, the exercise of communicating and persuading is not only a matter of presenting the issue of biosecurity, in this case weeds in KNP. It is also an exercise that engages in very material aspects of hiking and using the cleaning stations, such as fatigue, weather, queues, willingness to take one's turn, or the meaning of 'clean'. In identifying barriers as part of its process, CBSM takes a significant step beyond conventional programs based on education and information provision for weed management (Verbeek, van Oosterhout, and Gibney 2018); however, it may raise issues, such as notions of cleanliness, and invites lines of questioning, that are complex and embedded in society and culture beyond the specific site, issue, and actions (Biroscak 2018; Atchison 2019). Second, and relatedly, the message and cleaning stations are not just an exercise in park managers communicating with, or seeking to persuade, walkers. As CBSM recognises to some extent and as other invasive species research more specifically demonstrates, publics are active agents in their engagements with managers and invasive species (Graham 2014; Head et al. 2015; McKiernan 2018; Ernwein and Fall 2015). Thus, in engaging in CBSM strategies, park managers are not only asking things of walkers but are also inviting questions of themselves from walkers and are effectively entering into a range of commitments with walkers. Such commitments may include station maintenance and implicit or explicit claims regarding station cleaning efficacy. With CBSM, park managers are seeking to use norms to influence behaviour, but the norms at play may also extend to encompass the extent to which park managers themselves display norms relating to trustworthiness or reciprocity in ways that back up their requests of walkers. Put simply, managers will need to maintain the equipment so that they

maintain credibility with walkers who are being asked to consider footwear cleaning as an important act and to take time to stop and clean.

\section{Conclusion}

Around the world, tourism and visitors to conservation areas represent vectors for the potential distribution of invasive species. In alpine areas, such as KNP, climate change, visitor growth 
and changing access patterns may be altering the conditions under which such areas have been relatively resistant to invasive plants. In this context, our research provides insights for both park managers and the tourism industry to assist in managing biosecurity risks associated with visitors such as walkers. Moreover, our findings suggest the value of further research into the factors influencing cleaning station use and the extent to which they are relatively universal, or more dependent on national, cultural, or other contextual variables. Finally, and outside the scope of this research, there is also a need for research into the efficacy of cleaning stations in achieving their stated aims of removing sufficient seeds and pathogens to limit distribution. Such information will help determine the extent to which trailhead cleaning stations are a sufficient intervention, or whether and how they need to be part of broader efforts to influence park visitor biosecurity behaviour beyond the trailhead. 


\section{References}

Ajzen, Icek. 1991. "The theory of planned behavior." Organizational Behavior and Human Decision Processes 50 (2):179-211.

Alexander, Jake M., Jonas J. Lembrechts, Lohengrin A. Cavieres, Curtis Daehler, Sylvia Haider, Christoph Kueffer, Gang Liu, et al. 2016. "Plant invasions into mountains and alpine ecosystems: current status and future challenges." Alpine Botany 126 (2):89103. doi: 10.1007/s00035-016-0172-8.

Aley, Joanne , and Edy MacDonald. 2019. "Mark II Prototype Cleaning Station compliance research report." New Zealand Department of Conservation, Accessed 26th July. www.kauridieback.co.nz.

Anderson, L.G, S Rocliffe, N.R Haddaway, and A.M Dunn. 2015. "The role of tourism and recreation in the spread of non-native species: A systematic review and metaanalysis." PLoS ONE 10, doi:10.1371/journal.pone.0140833 (10).

Ansong, M, and C Pickering. 2014. "Weed seeds on clothing: A global review." Journal of Environmental Management 144:203-11.

Atchison, Jennifer. 2019. "Thriving in the Anthropocene: Understanding Human-Weed Relations and Invasive Plant Management Using Theories of Practice." In Social Practices and Dynamic Non-Humans, edited by Cecily Maller and Yolande Strengers, 25-46. Springer.

Baird, Tim, C Michael Hall, and Pavel Castka. 2018. "New Zealand winegrowers attitudes and behaviours towards wine tourism and sustainable winegrowing." Sustainability $10(3): 797$.

Bear, Roxana, Wendy Hill, and Catherine M Pickering. 2006. "Distribution and diversity of exotic plant species in montane to alpine areas of Kosciuszko National Park." Cunninghamia 9 (4):559-70.

Benson, Matt, and Rashi Dixit. 2019. "Kauri Dieback Formative Research Report." Accessed 26th July. https://www.kauridieback.co.nz/media/1531/1-2010-kauri-diebackformative-research-report-synovate_final.pdf.

Biroscak, Brian J. 2018. "Policy, systems, and environmental change: Reflections and suggestions for social marketers." Social Marketing Quarterly 24 (3):127-31. 
Boon, Paul I., Martin Fluker, and Nassima Wilson. 2008. "A Ten-Year Study of the Effectiveness of an Educative Programme in Ensuring the Ecological Sustainability of Recreational Activities in the Brisbane Ranges National Park, South-Eastern Australia." Journal of Sustainable Tourism 16 (6):681-97. doi: 10.1080/09669580802397053.

Bullock, James M., and Gesine Pufal. 2020. "Human-mediated dispersal as a driver of vegetation dynamics: A conceptual synthesis." Journal of Vegetation Science. doi: 10.1111/jvs. 12888 .

Burgin, Shelley, and Nigel Hardiman. 2012. "Is the evolving sport of mountain biking compatible with fauna conservation in national parks?" Australian Zoologist 36 (2):201-8. doi: 10.7882/az.2012.016.

Coleman, M. J., B. M. Sindel, A. W. Van Der Meulen, and I. J. Reeve. 2011. "The risks associated with weed spread in Australia and implications for natural areas." Natural Areas Journal 31 (4):368-76. doi: 10.3375/043.031.0407.

Colmar Brunton Consultants. 2019. "Kauri Dieback Survey Report." The Kauri Dieback Programme, Accessed 26th July. https://www.kauridieback.co.nz/media/1843/20160311-colmar-brunton-quantitativesurvey-report-final-version.pdf.

Curtis, Jim, Sam H. Ham, and Betty Weiler. 2010. "Identifying beliefs underlying visitor behaviour: A comparative elicitation study based on the theory of planned behaviour." Annals of Leisure Research 13 (4):564-89. doi: 10.1080/11745398.2010.9686865.

Department of Environment and Conservation. 2006. Plan of Management: Kosiuszko National Park. Sydney South: Department of Environment and Conservation NSW.

Eriksen, C., and N. Gill. 2010. "Bushfire and everyday life: Examining the awareness-action 'gap' in changing rural landscapes." Geoforum 41:814-25.

Ernwein, Marion, and Juliet J. Fall. 2015. "Communicating Invasion: Understanding social anxieties around mobile species." Geografiska Annaler: Series B, Human Geography 97 (2):155-67. doi: 10.1111/geob.12071.

Fishbein, Martin, and Icek Ajzen. 2011. Predicting and Changing Behavior: The Reasoned Action Approach: Psychology Press. 
Font, Xavier, and Scott McCabe. 2017. "Sustainability and marketing in tourism: its contexts, paradoxes, approaches, challenges and potential." Journal of Sustainable Tourism 25 (7):869-83. doi: 10.1080/09669582.2017.1301721.

Gates, KK, CS Guy, AV Zale, and TB Horton. 2009. "Angler awareness of aquatic nuisance species and potential transport mechanisms." Fisheries Management and Ecology 16 (6):448-56.

Gill, N., S. Graham, R. Cross, and E. Taylor. 2018. "Weed Hygiene Practices in Rural Industries and Public Land Management: Variable Knowledge, Patchy Implementation, Inconsistent Coordination." Journal of Environmental Management 223:140-9.

Graham, Sonia. 2014. "A new perspective on the trust power nexus from rural Australia." Journal of Rural Studies 36:87-98. doi: 10.1016/j.jrurstud.2014.06.010.

Green, Kevin M., Brian A. Crawford, Katherine A. Williamson, and Amielle A. DeWan. 2019. "A Meta-Analysis of Social Marketing Campaigns to Improve Global Conservation Outcomes." Social Marketing Quarterly 25 (1):69-87. doi: $10.1177 / 1524500418824258$.

Hall, C. Michael, Michael James, and Sandra Wilson. 2010. "Biodiversity, biosecurity, and cruising in the Arctic and sub-Arctic." Journal of Heritage Tourism 5 (4):351-64.

Hall, C. Michael. 2011. "Biosecurity, tourism and mobility: institutional arrangements for managing tourism-related biological invasions." Journal of Policy Research in Tourism, Leisure and Events 3 (3):256-80.

Hall, C. Michael. 2015. "Tourism and biological exchange and invasions: a missing dimension in sustainable tourism?" Tourism Recreation Research 40 (1):81-94. doi: 10.1080/02508281.2015.1005943.

Ham, S., T Brown, Jim Curtis, Betty Weiler, Michael Hughes, and Mark Poll. 2009. Promoting Persuasion In Protected Areas: A Guide For Managers Who Want To Use Strategic Communication To influence Visitor Behaviour. Gold Coast: Sustainable Tourism Cooperative Research Centre.

Hamilton, Mark A, Hillary Cherry, and Peter J Turner. 2015. "Hawkweed eradication from NSW: Could this be 'the first'?" Plant Protection Quarterly 30 (3):110. 
Head, L., B.M. Larson, R. Hobbs, J. Atchison, N. Gill, C. Kull, and H. Rangan. 2015. "Living with Invasive Plants in the Anthropocene: The Importance of Understanding Practice and Experience." Conservation and Society 13 (3):311-8.

Head, Lesley. 2017. "The social dimensions of invasive plants." Nature Plants 3 (6):17075.

Hobson, Kersty. 2017. "Why the devil does not have the best tunes: a response to Verissimo \& McKinley." Oryx 51 (1):21-. doi: 10.1017/S0030605316000326.

Hu, Ren, and Nicholas Gill. 2016. "Garden-Related Environmental Behavior and Weed Management: An Australian Case Study." Society \& Natural Resources 29 (2):14865. doi: 10.1080/08941920.2015.1045646.

Johnston, Stuart, and Andrew Growcock. 2005. Visiting the Kosciuszko Alpine Area. CRC for Sustainable Tourism, Gold Coast.

Juvan, Emil, and Sara Dolnicar. 2014. "The attitude-behaviour gap in sustainable tourism." Annals of Tourism Research 48:76-95. doi: https://doi.org/10.1016/j.annals.2014.05.012.

Kollmuss, Anja, and Julian Agyeman. 2002. "Mind the Gap: Why do people act environmentally and what are the barriers to pro-environmental behavior?" Environmental Education Research 8 (3):239-60. doi: 10.1080/13504620220145401.

Kueffer, C., K. McDougall, J. Alexander, C. Daehler, P. Edwards, S. Haider, A. Milbau, et al. 2013. "Plant Invasions into Mountain Protected Areas: Assessment, Prevention and Control at Multiple Spatial Scales." In Plant Invasions In Protected Areas: Patterns, Problems And Challenges, edited by L.C. Foxcroft, P. Pyšek, D.M. Richardson and P. Genovesi, 89-113. Dordrecht: Springer Netherlands.

Martin, Paul, and Donald W. Hine. 2017. "Using behavioural science to improve Australia's environmental regulation." The Rangeland Journal 39 (6):551-61. doi: https://doi.org/10.1071/RJ17105.

Martin, Victoria Y, Betty Weiler, Arianne Reis, Kay Dimmock, and Pascal Scherrer. 2017. "'Doing the right thing': how social science can help foster pro-environmental behaviour change in marine protected areas." Marine Policy 81:236-46.

Marzano, Mariella, Norman Dandy, Irena Papazova-Anakieva, Dimitrios Avtzis, Tom Connolly, René Eschen, Milka Glavendekić, Brett Hurley, Åke Lindelöw, and Dinka 
Matošević. 2016. "Assessing awareness of tree pests and pathogens amongst tree professionals: a pan-European perspective." Forest Policy and Economics 70:164-71.

McDougall, Keith L., John W. Morgan, Neville G. Walsh, and Richard J. Williams. 2005.

"Plant invasions in treeless vegetation of the Australian Alps." Perspectives in Plant Ecology, Evolution and Systematics 7 (3):159-71. doi:

https://doi.org/10.1016/j.ppees.2005.09.001.

McKenzie-Mohr, Doug. 2000. "New Ways to Promote Proenvironmental Behavior:

Promoting Sustainable Behavior: An Introduction to Community-Based Social

Marketing." Journal of Social Issues 56 (3):543-54. doi: doi:10.1111/00224537.00183 .

. 2011. Fostering Sustainable Behavior: An Introduction To Community-Based Social Marketing. Gabriola Island: New Society Publishers.

McKiernan, Shaun. 2018. "Managing invasive plants in a rural-amenity landscape: the role of social capital and Landcare." Journal of Environmental Planning and Management 61 (8):1419-37. doi: 10.1080/09640568.2017.1351930.

Metcalf, Alexander L., Justin W. Angle, Conor N. Phelan, B. Allyson Muth, and James C. Finley. 2019. "More "Bank" for the Buck: Microtargeting and Normative Appeals to Increase Social Marketing Efficiency." Social Marketing Quarterly 25 (1):26-39. doi: $10.1177 / 1524500418818063$.

Middlestadt, Susan E, Karabi Bhattacharyya, Julia Rosenbaum, Martin Fishbein, and Melissa Shepherd. 1996. "The use of theory based semistructured elicitation questionnaires: formative research for CDC's Prevention Marketing Initiative." Public Health Reports 111 (Suppl 1):18.

Morgan, John W., and Vanessa Carnegie. 2009. "Backcountry Huts as Introduction Points for Invasion by Non-native Species into Subalpine Vegetation." Arctic, Antarctic, and Alpine Research 41 (2):238-45. doi: 10.1657/1938-4246-41.2.238.

Mount, Ann., and Catherine M. Pickering. 2009. "Testing the capacity of clothing to act as a vector for non-native seed in protected areas." Journal of Environmental Management 91 (1):168-79. doi: 10.1016/j.jenvman.2009.08.002.

Pickering, Catherine M., Roxana Bear, and Wendy Hill. 2007. "Indirect Impacts of Nature Based Tourism and Recreation: The Association Between Infrastructure and the 
Diversity of Exotic Plants in Kosciuszko National Park, Australia." Journal of Ecotourism 6 (2):146-57. doi: 10.2167/joe162.0.

Pickering, Catherine Marina, Ann Mount, Matthias C Wichmann, and James M Bullock.

2011. "Estimating human-mediated dispersal of seeds within an Australian protected area." Biological Invasions 13 (8):1869-80.

Pickering, Catherine, and Ann Mount. 2010. "Do tourists disperse weed seed? A global review of unintentional human-mediated terrestrial seed dispersal on clothing, vehicles and horses." Journal of Sustainable Tourism 18 (2):239-56. doi: 10.1080/09669580903406613.

Pickering, Catherine M., Michael Ansong, and Erin Wallace. 2016. "Experimental assessment of weed seed attaching to a mountain bike and horse under dry conditions." Journal of Outdoor Recreation and Tourism 15:66-70.

Pickering, Catherine, Sebastian Dario Rossi, Ana Hernando, and Agustina Barros. 2018. "Current knowledge and future research directions for the monitoring and management of visitors in recreational and protected areas." Journal of Outdoor Recreation and Tourism 21:10-8. doi: https://doi.org/10.1016/j.jort.2017.11.002.

Randle, Melanie, Leonie Miller, Joanna Stirling, and Sara Dolnicar. 2016. "Framing Advertisements to Elicit Positive Emotions and Attract Foster Carers: An Investigation Into the Effects of Advertising On High-Cognitive-Elaboration Donations." Journal of Advertising Research 56 (4):456-69.

Rumpf, Sabine B, Inger Greve Alsos, and Chris Ware. 2018. "Prevention of microbial species introductions to the Arctic: The efficacy of footwear disinfection measures on cruise ships." NeoBiota 37:37.

Schwartz, F., B. D. Taff, B. Lawhon, and D. VanderWoude. 2018. "Mitigating Undesignated Trail Use: The Efficacy of Messaging and Direct Site Management Actions in an Urban-Proximate Open Space Context." Environmental Management 62 (3):458-73. doi: 10.1007/s00267-018-1054-1.

Seebens, Hanno, Tim M. Blackburn, Ellie E. Dyer, Piero Genovesi, Philip E. Hulme, Jonathan M. Jeschke, Shyama Pagad, et al. 2017. "No saturation in the accumulation of alien species worldwide." Nature Communications 8 (1):14435. doi: 10.1038/ncomms14435. 
Shannon, Caitriona, Claire H Quinn, Chloe Sutcliffe, Paul D Stebbing, Thomas Dally, Anita Glover, and Alison M Dunn. 2018. "Exploring knowledge, perception of risk and biosecurity practices among researchers in the UK: a quantitative survey." Biological Invasions:1-12.

Steckenreuter, A, and ID Wolf. 2013. "How to use persuasive communication to encourage visitors to pay park user fees." Tourism Management 37:58-70.

Tapp, Alan, and Sharyn Rundle-Thiele. 2016. "Social marketing and multidisciplinary behaviour change." In Beyond behaviour change: Key issues, interdisciplinary approaches and future directions, edited by Fiona Spotswood, 135-56. Bristol: Policy Press.

Tölkes, Christina. 2018. "Sustainability communication in tourism - A literature review." Tourism Management Perspectives 27:10-21.

Truong, V. Dao, and C. Michael Hall. 2017. "Corporate social marketing in tourism: to sleep or not to sleep with the enemy?" Journal of Sustainable Tourism 25 (7):884-902. doi: 10.1080/09669582.2016.1201093.

Urquhart, Julie, Clive Potter, Julie Barnett, John Fellenor, John Mumford, Christopher P Quine, and Helen Bayliss. 2017. "Awareness, concern and willingness to adopt biosecure behaviours: public perceptions of invasive tree pests and pathogens in the UK." Biological Invasions 19 (9):2567-82.

Vagias, Wade M, Robert B Powell, D Dewayne Moore, and Brett A Wright. 2014. "Predicting behavioral intentions to comply with recommended leave no trace practices." Leisure Sciences 36 (5):439-57.

van den Putte, Bas, and Godfried Dhondt. 2005. "Developing Successful Communication Strategies: A Test of an Integrated Framework for Effective Communication." Journal of Applied Social Psychology 35 (11):2399-420. doi: 10.1111/j.15591816.2005.tb02108.x.

Verbeek, B., E. van Oosterhout, and W. Gibney. 2018. "From little things big things grow A review of behaviour change initiatives for weeds management in NSW." In Proceedings of the 21st Australasian Weeds Conference. Sydney NSW, September 913. http://caws.org.nz/old-site/awc_contents.php?yr=2018. 
Ware, Chris, Dana M Bergstrom, Eike Müller, and Inger Greve Alsos. 2012. "Humans introduce viable seeds to the Arctic on footwear." Biological Invasions 14 (3):56777.

Wegner, S. 2019. "Factors Influencing Public Responses To Kauri Dieback Control Measures." The Kauri Dieback Programme, Accessed 26th July. https://www.kauridieback.co.nz.

Weiss, F., T. J. Brummer, and G. Pufal. 2016. "Mountain bikes as seed dispersers and their potential socio-ecological consequences." Journal of Environmental Management 181:326-32. doi: 10.1016/j.jenvman.2016.06.037. 